\title{
Proteomic DIGE analysis of the mitochondria-enriched fraction from aged rat skeletal muscle
}

\author{
Kathleen O'Connell and Kay Ohlendieck \\ Department of Biology, National University of Ireland, Maynooth, Co. Kildare, Ireland
}

Skeletal muscle aging is associated with a loss in tissue mass and contractile strength, as well as fiber type shifting and bioenergetic adaptation processes. Since mitochondria represent the primary site for energy generation via oxidative phosphorylation, we investigated potential changes in the expression pattern of the mitochondrial proteome using the highly sensitive DIGE approach. The comparative analysis of the mitochondria-enriched fraction from young adult versus aged muscle revealed an age-related change in abundance for 39 protein species. MS technology identified the majority of altered proteins as constituents of muscle mitochondria. An age-dependent increase was observed for NADH dehydrogenase, the mitochondrial inner membrane protein mitofilin, peroxiredoxin isoform PRX-III, ATPase synthase, succinate dehydrogenase, mitochondrial fission protein Fis1, succinate-coenzyme A ligase, acyl-coenzyme A dehydrogenase, porin isoform VDAC2, ubiquinol-cytochrome c reductase core I protein and prohibitin. Immunoblotting, enzyme testing and confocal microscopy were used to validate proteomic findings. The DIGE-identified increase in key mitochondrial elements during aging agrees with the concept that sarcopenia is associated with a shift to a slower contractile phenotype and more pronounced aerobic-oxidative metabolism. This suggests that mitochondrial markers are reliable candidates that should be included in the future establishment of a biomarker signature of skeletal muscle aging.

\section{Keywords:}

Aging / Animal proteomics / DIGE / Mitochondria / Sarcopenia / Skeletal muscle proteomics

\section{Introduction}

Mitochondria are highly evolved organelles that are enclosed by a smooth outer membrane and a heavily folded inner membrane structure and are involved in various cellular functions [1]. Both mitochondrial membrane systems [2], as well as dynamic contact sites between the outer and inner membrane [3-5], play a key role in energy metabolism and protein transport [6]. In most eukaryotic cells, mitochondria represent the primary site for energy generation via oxidative phosphorylation [7]. In addition, mitochondria are involved in intermediary metabolism, cell cycle progression,

Correspondence: Professor Kay Ohlendieck, Department of Biology, National University of Ireland, Maynooth, Co. Kildare, Ireland

E-mail: kay.ohlendieck@nuim.ie

Fax: +353-1-708-3845

Abbreviation: DAPI, diamidino-phenylindole
Received: July 2, 2009

Revised: September 7, 2009 Accepted: September 14, 2009 calcium signaling and the regulation of apoptosis, as well as the production of heme and iron-sulfur clusters [1]. Mitochondria are believed to have originated as endosymbionts of a primordial eukaryote and certain mitochondrial proteins are encoded by a unique mitochondrial genome. Approximately 1500 different mitochondrial proteins exist [2], whereby the mammalian mitochondrial proteome exhibits considerable tissue heterogeneity [8-11]. Altered expression levels within the mitochondrial proteome influence many aspects of normal development, diseases and the aging process [12].

Mitochondrial dysfunction and oxidative stress appear to be associated with numerous cardiac pathologies such as congestive heart failure, ischemia reperfusion injury and cardiomyopathy [13], skeletal muscle disorders including mitochondrial myopathies and sarcopenia of old age [14] and aging-related neurodegenerative diseases such as Alzheimer's disease, amyotrophic lateral sclerosis and Parkinson's disease [15]. In this respect, two aspects of 
altered mitochondrial activity are crucial for the cellular aging process. Firstly, the age-dependent decline in mitochondrial function adversely affects essential ATP-dependent processes [16] and, secondly, the increased release of ROS from the mitochondrial respiratory chain triggers severe oxidative stress in aged cells [17-19]. Abnormal mitochondrial metabolism is also important for skeletal muscle aging, as recently reviewed by Figueiredo et al. [20]. Age-related muscle degeneration is associated with enhanced production of mitochondrial ROS, impaired mitochondrial bioenergetic function, increased mitochondrial apoptotic susceptibility and a reduced transcriptional drive for mitochondrial biogenesis [21, 22].

The age-related decrease in skeletal muscle mass and function is probably due to a multi-factorial pathology and is believed to play a crucial part in physical disability, frailty and loss of independence in the aged population [23]. The fact that skeletal muscles represent the most abundant tissue type in the body and that muscles exhibit an extensive capacity to adapt to altered functional and metabolic demands [24], results in a considerable influence of neuromuscular abnormalities on whole-body homeostasis [25]. Age-dependent skeletal muscle degeneration has been termed sarcopenia of old age [26] and is one of the most striking features in the elderly $[27,28]$. The decline in muscle strength even affects the most physically active master athletes in the group of aged individuals [29] and improved nutritional intake and exercise intervention can only partially prevent sarcopenia [30]. Initial proteomic studies on crude total skeletal muscle extracts have identified mitochondrial enzymes as potential biomarkers of agerelated fiber wasting, including various components of the citric acid cycle and oxidative phosphorylation [31-37]. Proteomic profiling of aged muscle has demonstrated substantial alterations in muscle proteins involved in key metabolic pathways, the regulation and maintenance of the actomyosin apparatus, myofibrillar remodeling and the cellular stress response [34]. A complex etiology appears to be the basis for a slower-twitching aged fiber population, which exhibits a shift to more aerobic-oxidative metabolism [38].

Subproteomic studies have focused predominantly on mitochondria due to their important role in bioenergetics, disease and aging [2, 39-41], especially the heart [42-44] and liver tissue $[45,46]$. Comparative transcriptomic and proteomic studies have also been initiated to determine global changes in mitochondria from young versus aged skeletal muscle [47-51]. Based on these findings, we have conducted here a refined analysis of the aged mitochondrial proteome from rat skeletal muscle using the highly sensitive DIGE technique [52-54]. As reviewed by Doran et al. [55], small rodents are excellent models for the discovery of new reliable biomarkers, for the optimization of diagnostic procedures and the development of new treatment options for skeletal muscle disorders. A well-established animal model of sarcopenia is represented by 26 -month-old rat skeletal muscle [33-37]. A proteomic study by Piec et al. [31] revealed similar protein expression patterns between young and adult rat skeletal muscles, but considerable alterations in older animals. We have therefore performed a proteomic survey of mitochondrial preparations from 3-month-old versus 26-month-old muscles, representing young adult versus senescent tissues, respectively. The proteomic DIGE analysis presented here shows a clear age-related increase in key mitochondrial proteins, such as NADH dehydrogenase, the mitochondrial inner membrane protein mitofilin, peroxiredoxin isoform PRX-III, ATPase synthase, succinate dehydrogenase, mitochondrial fission protein Fis1, succinate-coenzyme A ligase, acyl-coenzyme A dehydrogenase, porin isoform VDAC2, ubiquinol-cytochrome c reductase core I protein and prohibitin. These findings agree with the idea that sarcopenia of old age is associated with an agerelated shift to a slower contractile phenotype and a bioenergetic adaptation to more aerobic-oxidative metabolism.

\section{Materials and methods}

\subsection{Materials}

IPG drystrips for 2-D gel electrophoresis, ampholytes, cover fluid, ACN, the PlusOne Silver Stain kit, and CyDye DIGE fluor minimal dyes $\mathrm{Cy} 3$ and $\mathrm{Cy} 5$ were purchased from Amersham Bioscience/GE Healthcare (Little Chalfont, Bucks, UK). Acrylamide stock solutions were obtained from National Diagnostics (Atlanta, GA, USA). Pre-cast mini gels were from Thermo Fisher Scientific (Waltham, MA, USA). GE buffer systems, protein molecular weight ladders and Bradford reagent were purchased from BioRad Laboratories (Hemel-Hempstead, Herts, UK). Sequencing grade-modified trypsin was purchased from Promega (Madison, WI, USA). LC-MS Chromasolv water and formic acid were from Fluka (Milwaukee, WI, USA). Protease inhibitors were obtained from Roche Diagnostics (Mannheim, Germany). Nitrocellulose transfer stacks were from Invitrogen (Carlsbad, CA, USA). Chemiluminescence substrate was purchased from Roche Diagnostics. X-ray films were from Fuji Photo Film (Tokyo, Japan). Primary antibodies were obtained from Abcam, Cambridge, UK (ab28172 to prohibitin; ab76241 to DJ1 protein; ab1473 to F1-ATPase; ab66484 to mitofilin; ab48139 to succinate dehydrogenase; ab2101 to lactate dehydrognase), Santa Cruz Biotechnology, Santa Cruz, CA, USA (ab-sc27992 to succinate dehydrogenase), Affinity Bioreagents, Golden, CO, USA (MA3-912 to fast SERCA1 $\mathrm{Ca}^{2+}$-ATPase, MA3-921 to $\alpha_{2}$-DHPR), Sigma, Dorset, UK (m4276 to fast myosin) and Novacastra Laboratories, Newcastle upon Tyne, UK (antibody NCL-b-DG to $\beta$-dystroglycan). All secondary antibodies used were obtained from Chemicon International (Temecula, CA, USA). For microscopy, Superfrost Plus positively-charged microscope slides were purchased from Menzel Glässer (Braunschweig, Germany), optimum cutting temperature 
(OCT) compound was from Sakura Finetek Europe B.V (Zoeterwoude, the Netherlands), and $p$-phenylenediamineglycerol from Citifluor (London, UK). Ultra-pure lysine for quenching the DIGE labeling reaction, DNase-I enzyme, developer, diamidino-phenylindole (DAPI), the hydrophobic liquid blocker PAP pen, fixer and replenisher, as well as all other analytical-grade chemicals were purchased from Sigma Chemical Company.

\subsection{Animal model of sarcopenia}

The gastrocnemius muscle from 26-month-old Wistar rats was used as an established animal model of sarcopenia and compared to young adult skeletal muscle from 3-month-old Wistar rats. The biological suitability of senescent rat muscle as a model tissue to investigate fiber aging has been previously shown by various cell biological, physiological and anatomical studies, as recently reviewed by Doran et al. [55]. In analogy to age-related changes in human skeletal muscles, senescent rat muscles exhibit altered fiber type proportions, changed fiber size, fiber degeneration, the loss of whole motor units, denervation-reinnervation cycles resulting in the incomplete recruitment of aged fibers and a reduced speed of contraction [28]. These pathoanatomical and pathophysiological parameters have made aged rat muscles a convenient model system of aging that is routinely used in proteomic profiling studies [31, 33-38]. For our comparative DIGE analysis of the young versus the aged mitochondrial proteome, freshly dissected gastrocnemius specimens were obtained from the Animal Facility of the Department of Physiology, Trinity College Dublin. Rats were kept at a standard light-dark cycle, fed at libidum and were unrestricted in their movement in standard animal house cages [37].

\subsection{Extraction of total skeletal muscle protein complement}

Preparation of crude skeletal muscle extracts was carried out as previously described in detail [56]. Frozen muscle specimens were ground in the presence of liquid nitrogen into a fine powder using a mortar and pestle. Equal quantities of $100 \mathrm{mg}$ wet weight of young and aged gastrocnemius muscle were used and the resulting powder was placed into $1 \mathrm{~mL}$ of homogenization buffer (0.5 M HEPES, pH 7.4, $200 \mathrm{mM}$ EGTA, $10 \% \mathrm{w} / \mathrm{v}$ sucrose, $3 \mathrm{mM} \mathrm{MgCl} 2,0.1 \% \mathrm{w} / \mathrm{v}$ $\mathrm{NaN}_{3}$ ). Samples were homogenized for $10 \mathrm{~s}$ with a Sonoplus HD 2200 apparatus from Bandelin (Berlin, Germany). To reduce the interference by excess DNA, $2 \mu \mathrm{L}$ of DNase- 1 (200 units) were added per $100 \mu \mathrm{L}$ of lysis buffer. The buffer was also supplemented with a protease inhibitor cocktail [56] to avoid protein degradation. Suspensions were incubated on ice, with gentle vortexing every $10 \mathrm{~min}$ for $10 \mathrm{~s}$, for $4 \mathrm{~h}$ and then centrifuged for $20 \mathrm{~min}$ at $20000 \times \mathrm{g}$ in a model $5417 \mathrm{R}$ centrifuge from Eppendorf (Hamburg, Germany). Protein concentration was determined by the Bradford method [57].

\subsection{Preparation of mitochondria-enriched fraction from skeletal muscle}

Muscle mitochondria were isolated according to the method of Kane et al. [58] with slight modifications, as outlined below. The successful enrichment of mitochondria by differential centrifugation was judged by immunoblot analysis. Two grams of young and aged gastrocnemius tissue was cut into small pieces and homogenized in $20 \mathrm{~mL}$ of homogenization buffer (2 mM HEPES, pH 7.4, $220 \mathrm{mM}$ mannitol, $70 \mathrm{mM}$ sucrose), supplemented with a protease inhibitor cocktail [56]. The resulting mixture was centrifuged at $1100 \times \mathrm{g}$ for $5 \mathrm{~min}$ at $4^{\circ} \mathrm{C}$ to remove cellular debris and nuclei. The mitochondria-containing supernatant was retained. The pellet was resuspended in $10 \mathrm{~mL}$ of above described homogenization buffer and re-centrifuged. Again the supernatant was retained and the pellet resuspended in $5 \mathrm{~mL}$ of buffer. This step was repeated once more with the pellet being resuspended in $2.5 \mathrm{~mL}$ of buffer. The supernatants from all extraction steps were combined and centrifuged at $7000 \times \mathrm{g}$ for $15 \mathrm{~min}$. The resulting pellet was resuspended in the above-described buffer system, containing a freshly prepared protease inhibitor cocktail, and centrifuged at $20000 \times \mathrm{g}$ for $15 \mathrm{~min}$ to sediment the mitochondrial fraction. This step was repeated three times with the pellet retained each time. After the final centrifugation step, the mitochondrial pellets were combined and gently resuspended in either $500 \mu \mathrm{L}$ of homogenization buffer for immunoblot analysis or in 2-DE lysis buffer (7 M urea, $2 \mathrm{M}$ thiourea, $4 \% \mathrm{w} / \mathrm{v}$ CHAPS) for gel electrophoretic separation. Samples for DIGE analysis were kept at a $\mathrm{pH}$ value of 8.5 [52]. To estimate mitochondrial enrichment following differential centrifugation, citrate synthase activity [59] was determined in crude versus mitochondrial samples from young and aged specimens. The average increase of marker enzyme activity in the mitochondria-enriched fraction as compared to total muscle extracts was 5.1-fold in young adult muscle and 5.3-fold in aged muscle. Protein content of the mitochondria-enriched fraction from young adult and aged skeletal muscle was ascertained by the Bradford assay system [57]. The average yield of the mitochondria-enriched fraction was 18 and $23 \%$ in young adult and aged preparations, respectively.

\subsection{Immunoblot analysis}

The fate of marker proteins during the mitochondrial isolation procedure and the validation of expression changes in mitochondrial proteins as judged by DIGE analysis was carried out by standard 1-D immunoblotting [33]. For routine analyses, skeletal muscle proteins were separated on 
a pre-cast 4-20\% gel system from Thermo Fisher Scientific. For silver staining and immunoblotting experiments, $10 \mu \mathrm{g}$ and $25 \mu \mathrm{g}$ of muscle protein was run per gel lane, respectively. Samples were boiled for $10 \mathrm{~min}$ in Laemmli-type buffer containing $350 \mathrm{mM}$ DTT prior to loading onto a MiniProtean-3 gel system (BioRad Laboratories). Gels were electrophoresed at $80 \mathrm{~V}$ until the tracking dye ran off the end of the gel. Protein gels to be silver-stained were placed in fixing solution (30\% v/v ethanol, $10 \% \mathrm{v} / \mathrm{v}$ acetic acid). Silver staining was performed using the PlusOne Silver Staining kit from Amersham, which is based on the methodology of Heukeshoven and Dernick [60]. The protocol was carried out as per the manufacturer's instructions. Stained gels were scanned using an Umax image scanner from Amersham Biosciences/GE Healthcare. Gels for immunoblotting were transferred to an iblot transfer unit from Invitrogen for semi-dry blotting. Electrophoretic transfer was carried out for $6 \mathrm{~min}$. The resulting protein-containing nitrocellulose membranes were blocked in a milk protein solution for $1 \mathrm{~h}$ and then incubated overnight with gentle agitation with sufficiently diluted primary antibody, diluted in blocking solution containing $5 \% \mathrm{w} / \mathrm{v}$ fat-free milk powder in PBS $(0.9 \% \mathrm{w} / \mathrm{v} \mathrm{NaCl}, 50 \mathrm{mM}$ sodium phosphate, $\mathrm{pH} 7.4)$. Blots were washed twice with blocking solution for $10 \mathrm{~min}$ before incubation for $1 \mathrm{~h}$ with secondary peroxidase-conjugated antibodies, diluted in blocking solution. Following two washing steps with blocking solution and then two rinsing steps with PBS, immunodecorated bands were visualized by the enhanced chemiluminescence method [61]. Exposure of X-ray films usually took 1-5 min. For proper comparison, all blots probed with the same primary antibody were washed in the same solutions and exposed to X-ray film for the same amount of time.

\subsection{DIGE analysis of the mitochondrial muscle proteome}

Our laboratory has extensive experience with the proteomic analysis of aged muscle tissues [33, 34, 37] and has previously optimized the DIGE method for studying various skeletal muscle protein complements [62-64]. The proteomic profiling of the mitochondrial proteome from young adult versus aged skeletal muscle presented here has taken into account the general recommendations by Lilley and coworkers [65-67] for maximizing sensitivity for detecting changes in protein expression using minimal CyDyes. Overall, we used five young adult and five old animals in our DIGE analysis. In total, one gel was used for each animal, in both the pH 4-7 and pH 6-11 category. Thus, a total of 20 DIGE gels were run and analyzed. Cy3 and Cy5 dyes were reconstituted as a stock solution of $1 \mathrm{mM}$ in fresh dimethylformamide. Prior to labeling, the stock solutions were diluted to a working solution of $0.2 \mathrm{mM}$. Individual $25-\mu \mathrm{g}$ samples representing young adult mitochondria or aged mitochondria were minimally labeled with 200 pmols of Cy3 by standard procedure [52]. An internal pooled standard, consisting of equal quantities of protein from all investigated samples, was labeled at a ratio of $200 \mathrm{pmol} \mathrm{Cy} 5$ dye to $25 \mu \mathrm{g}$ of protein. Samples at $\mathrm{pH} 8.5$ were mixed with the appropriate amount of dye, vortexed briefly and incubated on ice for $30 \mathrm{~min}$ in the dark. The reaction was quenched by $10 \mathrm{mM}$ lysine, which was incubated with the dye-protein mixture for $10 \mathrm{~min}$ on ice in the dark. Samples were immediately loaded onto IPG strips for electrophoretic separation in the first dimension. For IEF, $\mathrm{pH} 4-7$ and $\mathrm{pH}$ 6-11 IPG strips were rehydrated for $12 \mathrm{~h}$ in rehydration buffer (7 M urea, $2 \mathrm{M}$ thiourea, $65 \mathrm{mM}$ CHAPS, 5\% v/v ampholytes) in a re-swelling tray from Amersham Biosciences/GE Healthcare. After re-swelling, the IPG strips were loaded gel side up in an Amersham Ettan IPGphor manifold and covered with $108 \mathrm{~mL}$ of cover fluid. An appropriate amount of sample, along with an equal volume of $2 \times$ sample buffer ( $7 \mathrm{M}$ urea, $2 \mathrm{M}$ thiourea, $65 \mathrm{mM}$ CHAPS, $2 \%$ ampholytes and 2\% DTT), was added by anodic cup loading to the strips and run on an Amersham IPGphor IEF system, employing the following running conditions: $100 \mathrm{~V}$ for $2 \mathrm{~h}, 500 \mathrm{~V}$ for $1.5 \mathrm{~h}, 1000 \mathrm{~V}$ for $1 \mathrm{~h}, 2000 \mathrm{~V}$ for $1 \mathrm{~h}$, $4000 \mathrm{~V}$ for $1 \mathrm{~h}, 6000 \mathrm{~V}$ for $1 \mathrm{~h}, 8000 \mathrm{~V}$ for $1 \mathrm{~h}, 500 \mathrm{~V}$ for $4 \mathrm{~h}$ and finally $8000 \mathrm{~V}$ for $1 \mathrm{~h}$. Following IEF, IPG strips were equilibrated twice for $20 \mathrm{~min}$ in $6 \mathrm{M}$ urea, $30 \% \mathrm{w} / \mathrm{v}$ glycerol, $2 \% \mathrm{w} / \mathrm{v}$ SDS, $100 \mathrm{mM}$ Tris-HCl, pH 8.8, whereby the first incubation step was preformed with the addition of $100 \mathrm{mM}$ DTT and the second incubation step with $0.25 \mathrm{M}$ iodoacetamide. The strips were briefly washed in SDS running buffer (125 mM Tris, $0.96 \mathrm{M}$ glycine, $0.1 \% \mathrm{w} / \mathrm{v}$ SDS) and placed on top of $12.5 \% \mathrm{w} / \mathrm{v}$ resolving gels and set in place using a $1 \% \mathrm{w} / \mathrm{v}$ agarose sealing gel. The gel electrophoretic separation of the mitochondrial muscle proteome in the second dimension was carried out by standard SDS-PAGE using an Amersham Ettan DALT-Twelve system. Gels were electrophoresed at $1.5 \mathrm{~W}$ per gel until the bromophenol blue dye front had just run off the gel.

\subsection{Image acquisition and data analysis}

CyDye-labelled proteins were visualized using a Typhoon Trio variable mode imager from Amersham Biosciences/GE Healthcare at a scanning wavelength of $\lambda=550 \mathrm{~nm}$ for Cy3 and $\lambda=650 \mathrm{~nm}$ for Cy5 labelled muscle proteins. The PMT values for gels analyzed were between $500 \mathrm{~V}$ and $700 \mathrm{~V}$ and the maximum pixel volume was between 80000 and 90000 . Scanning was performed at $100 \mu \mathrm{m}$ resolution [62-64]. The gel images were then analyzed using Progensis Samespots analysis software version 3.2.3 from Non Linear Dynamics (Newcastle upon Tyne, UK). All analytical gels were aligned to a reference gel. Following detection and filtering of spots, images were separated into groups (young adult versus old) and analyzed to determine significant changes in 2-D spot abundance. A hit list was generated of protein species that changed in abundance. An Anova score was included for 
each spot and any muscle proteins with an Anova score above 0.5 were excluded from further consideration. Similarly, PCA analysis was also carried out and any spots with a power value below 0.8 were also excluded. The same proteomic analysis was separately applied to the ten sets of pH 4-7 and ten sets of pH 6-11 gels. Any 2-D spots with a change in abundance that met all above outlined criteria were subsequently identified by LC MS analysis.

\subsection{LC MS analysis of mitochondrial proteome}

Prior to MS-based identification, 2-D protein spots of interest were manually excised from silver-stained gels, which had been loaded with $100 \mu$ g total protein. Spots were de-stained, reduced and alkylated before overnight digestion at $37^{\circ} \mathrm{C}$ with $100 \mathrm{ng}$ trypsin per protein spot [34]. Samples were then spun and the supernatant transferred to fresh tubes. Peptides were further extracted by the addition of $100 \mu \mathrm{L}$ extraction buffer (1:2 TFA:ACN) for $15 \mathrm{~min}$ at $37^{\circ} \mathrm{C}$. Samples were spun and supernatants added to those from the previous step. Extracts were dried completely in a vacuum centrifuge and peptides resuspended in $20 \mu \mathrm{L}$ of $0.1 \%$ formic acid. This peptide mix was then transferred to HPLC vials. Samples were analyzed on an Agilent 6340 Ion Trap LC/MS (Agilent Technologies, Santa Clara, CA, USA) on a gradient of $5-100 \%$ ACN $/ 0.1 \%$ formic acid for $45 \mathrm{~min}$. Separation of peptides was performed with a nanoflow Agilent 1200 series system, equipped with a Zorbax 300SB C18 $5 \mu \mathrm{m}, 4 \mathrm{~mm} 40 \mathrm{~nL}$ pre-column and an Zorbax 300SB C18 $5 \mu \mathrm{m}, 43 \mathrm{~mm} \times 75 \mu \mathrm{m}$ analytical reversed phase column using the HPLC-Chip technology. Mobile phases utilized were A: $0.1 \%$ formic acid; B: $50 \%$ ACN and $0.1 \%$ formic acid. Samples $(15 \mu \mathrm{L})$ were loaded into the enrichment at a capillary flow rate set to $4 \mu \mathrm{L} / \mathrm{min}$ with a mix of $A$ and $B$ at a ratio 19:1. Tryptic peptides were eluted with a linear gradient of $10-90 \%$ solvent B over $40 \mathrm{~min}$ with a constant nano pump flow of $0.60 \mathrm{~mL} / \mathrm{min}$. A 10-min post time of Solvent A was used to remove sample carryover. The capillary voltage was set to $1700 \mathrm{~V}$. The flow and the temperature of the drying gas were $4 \mathrm{~L} / \mathrm{min}$ and $300^{\circ} \mathrm{C}$, respectively. Identified peptides were utilized to determine the protein species present in distinct 2-D spots. Database searches were carried out with Mascot MS/MS Ion search (Matrix Science, London, UK; MSDB database, release 20063108). All searches used "Rattus norvegicus" as taxonomic category and the following parameters: (i) two missed cleavages by trypsin; (ii) mass tolerance of precursor ions $\pm 2.5 \mathrm{Da}$ and product ions $\pm 0.7 \mathrm{Da}$; (iii) carboxymethylated cysteines fixed modification; and (iv) oxidation of methionine as variable modification.

\subsection{Enzyme assays}

To evaluate potential changes in the enzyme activity of select marker proteins, established assay systems were employed. NADH dehydrogenase activity was measured by the oxidation of $\mathrm{NADH}$ in $50 \mathrm{mM}$ sodium phosphate, $\mathrm{pH}$ 6.5, $1 \mathrm{mM}$ EDTA, $100 \mu \mathrm{M} \mathrm{Q}_{1}, 2 \mathrm{mM} \mathrm{KCN}$ and $200 \mu \mathrm{M}$ $\mathrm{NADH}$. Measurements were carried out on a Cary Varian Eclipse fluorescent spectrophotometer from Varian (Palo Alto, CA, USA) for $10 \mathrm{~min}$ with an excitation and emission wavelength of 340 and $460 \mathrm{~nm}$, respectively [68]. Aldolase and succinate dehydrogenase activity were determined on a Lambda 35 UV-Vis spectrophotometer from PerkinElmer Life and Analytical Sciences (Waltham, MA, USA). Aldolase activity was measured in $57 \mathrm{mM}$ fructose-1,6-bisphosphate, $0.05 \mathrm{mM}$ EDTA and $1.9 \mathrm{mM}$ hydrazine sulfate [69]. The formation of hydrazone was measured at $240 \mathrm{~nm}$ for $10 \mathrm{~min}$. Succinate dehydrogenase activity was measured in $0.1 \mathrm{mM}$ EDTA, $0.1 \% \mathrm{w} / \mathrm{v}$ BSA, $3 \mathrm{mM}$ sodium azide, $100 \mu \mathrm{M}$ 2,6-dichlorophenol-indophenol, $50 \mathrm{mM}$ potassium phosphate and $20 \mathrm{mM}$ succinate [70]. Reactions were started by the addition of succinate and the decrease in absorbance measured at $680 \mathrm{~nm}$ for $10 \mathrm{~min}$. To determine mitochondrial enrichment following differential centrifugation, citrate synthase activity was determined with Sigma Enzyme Kit CS0720, which is based on the method originally described by Srere [59].

\subsection{Confocal microscopy}

The subcellular localization of mitochondrial marker proteins was carried out by confocal microscopy, as previously described in detail [56]. Tissue sections derived from young adult and aged gastrocnemius muscle were mounted on a cyrocassette with OCT compound and frozen at a temperature of $-20^{\circ} \mathrm{C}$. Transverse cryosections of $10-\mu \mathrm{m}$ thickness were cut on a Shandon Cryotome (Life Sciences International, Cheshire, UK) and then transferred to Superfrost Plus positively-charged microscopy slides. Sections were fixed and permeabilized by being submerged in ice-cold $100 \%$ acetone for $5 \mathrm{~min}$. Tissue sections were left to dry at room temperature before being washed briefly in ice-cold PBS [56]. After the removal of excess buffer, a layer of wax was drawn around the sample with a Liquid Blocker Super PAP Pen. Sections were submersed in blocking solution $(0.2 \% \mathrm{w} / \mathrm{v}$ BSA, $0.2 \% \mathrm{v} / \mathrm{v}$ Triton $\mathrm{X}-100$, and $2.5 \%$ $\mathrm{v} / \mathrm{v}$ goat serum in PBS) for $30 \mathrm{~min}$, and then incubated with primary antibodies diluted in $0.2 \% \mathrm{w} / \mathrm{v}$ BSA and $0.2 \% \mathrm{v} / \mathrm{v}$ Triton X-100 in phosphate-buffered saline for $4 \mathrm{~h}$. Subsequently sections were washed twice for $30 \mathrm{~min}$ in above solution omitting antibodies. Sufficiently diluted secondary antibodies were placed on tissue sections for $1 \mathrm{~h}$, followed by the above-described washing steps. Fiber nuclei were labelled with $1 \mu \mathrm{g} / \mathrm{mL}$ DAPI for $30 \mathrm{~min}$ [56]. One drop of $p$ phenylenediamine-glycerol was applied to the immunodecorated tissue sections and then coverslips carefully placed over the sections, avoiding the introduction of air bubbles. Coverslips were sealed in place with a thin layer of clear nail 
varnish. Immunofluorescent labelling was visualized with an Olympus IX81 microscope and Olympus Fluoroview for 1.5 software (Olympus Life and Material Science Europe, Hamburg, Germany).

\section{Results}

\subsection{Isolation of mitochondria-enriched fraction for proteomic analysis}

In contrast to mitochondrial preparations from liver, the same type of organelle is relatively difficult to isolate from contractile tissues, which are tougher to homogenize and more difficult to fractionate without considerable levels of cross-contamination derived from other cellular structures. This concerns especially the entrapment or adsorption of elements belonging to the contractile apparatus, which makes up approximately half of all muscle proteins, and components associated with the extensive membrane systems of the sarcolemma, transverse tubules and sarcoplasmic reticulum. However, the application of lengthy and excessive separation and washing steps for producing highly purified mitochondria may introduce potential artifacts that considerably complicate comparative proteomic studies. Therefore, an analytical compromise was applied in this study in order to overcome the under-representation of the mitochondrial protein complement in crude total muscle extracts. An efficient and fast differential centrifugation protocol was employed that used a minimum of separation steps [58] and resulted in a subcellular fraction that was sufficiently enriched in muscle mitochondria. To evaluate the yield of mitochondrial elements in the final preparation and the potential crosscontamination with other muscle components, an immunoblot survey was conducted. Silver-stained 1-D gels clearly showed a considerably different protein band pattern between crude extracts and the mitochondria-enriched farction (Fig. 1A). As illustrated in Fig. 1B-F, antibodies against abundant markers of the contractile apparatus, sarcolemma, transverse tubules, sarcoplasmic reticulum and cytosol were employed. Immunodetection clearly showed a drastic reduction in the sarcolemmal marker $\beta$-dystroglycan, the sarcoplasmic reticulum $\mathrm{Ca}^{2+}$-ATPase SERCA1, the $\alpha_{2}$-subunit of the transverse-tubular dihydropyridine receptor, the fast-twitch MHCf isoform of the contractile protein myosin and the cytosolic marker enzyme lactate dehydrogenase in the mitochondrial preparations from both young adult and aged skeletal muscles. In contrast, antibody labeling experiments for the identification of markers of the inner mitochondrial membrane, the mitochondrial matrix and the outer mitochondrial membrane, i.e. succinate dehydrogenase, malate dehydrogenase and the porin isoform VDAC1, respectively, showed an enrichment of these proteins in the mitochondrial fraction (Fig. 1G-I).

\subsection{DIGE analysis of mitochondria from aged skeletal muscle}

In contrast to conventional protein dye staining methods, DIGE analysis is a highly accurate quantitative technique that enables multiple protein samples to be separated on the same 2-D gel, thereby greatly reducing the introduction of potential artifacts due to gel-to-gel variations [52-54]. This makes comparative DIGE approaches one of the most powerful analytical tools for conducting comparative biochemical investigations. Based on the previously published findings from proteomic profiling exercises using crude total muscle extracts [31-36] and initial proteomic studies on the mitochondrial complement [47-51], we have conducted here a refined analysis of the mitochondriaenriched fraction from young adult versus aged rat gastrocnemius muscle. With the help of a Typhoon Trio variable imager and Progenesis 2-D analysis software, 39 protein species out of 1448 detectable 2-D spots were found to be differentially expressed. Representative DIGE gels with electrophoretically separated mitochondrial proteins from young adult versus senescent muscle fibers are shown for the pH 4-7 (Fig. 2A-D) and $\mathrm{pH}$ 6-11 (Fig. 2E-H) range. The lower and higher $\mathrm{pH}$-scale of the two different IEF approaches resulted in the separation of 726 and 722 2-D protein spots, respectively, whereby unsurprisingly a certain amount of muscle proteins in the neutral $\mathrm{pH}$ range overlapped between the two analytical DIGE gels (Fig. 2A-H).

\subsection{Proteomic profiling of aged muscle mitochondria}

A list of the 39 DIGE-identified protein species that exhibited a drastically altered expression level in aged mitochondria is shown in Supporting Information Table 1. The table combines data from both $\mathrm{pH} 4-7$ and $\mathrm{pH}$ 6-11 gels and outlines matched peptide sequences, percentage sequence coverage, Mascot score, the relative molecular mass, pI value, protein accession number and fold-change of individual proteins affected during fiber aging. The majority of identified muscle proteins were found to be constituents of mitochondria, further emphasizing the above described successful subcellular fractionation protocol for the enrichment of mitochondria. In addition to mitochondrial markers, glycolytic enzymes, metabolic transporters and a contractile element were also identified by MS analysis. Mitochondrial proteins with an age-dependent alteration in abundance ranged in molecular mass from apparent 17 to $81 \mathrm{kDa}$ and covered a $\mathrm{pI}$-range from approximately 5 to 9 . To be able to correlate MS-identified protein species (Supporting Information Table 1) with distinct 2-D spots of altered density, a DIGE Cy5 master gel combining both analyzed $\mathrm{pH}$-ranges is shown in Fig. 3. For optimum orientation, a landmark 2-D spot with unchanged abundance is indicated and marked $\mathrm{mCK}$, representing mitochondrial creatine 


\section{Young adult vs. aged SKELETAL MUSCLE}

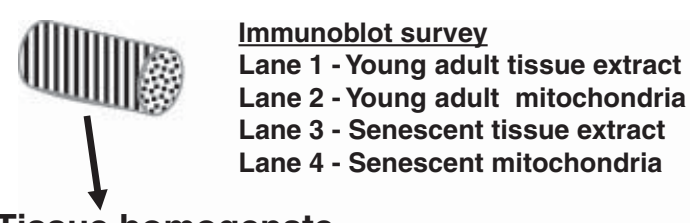

Tissue homogenate

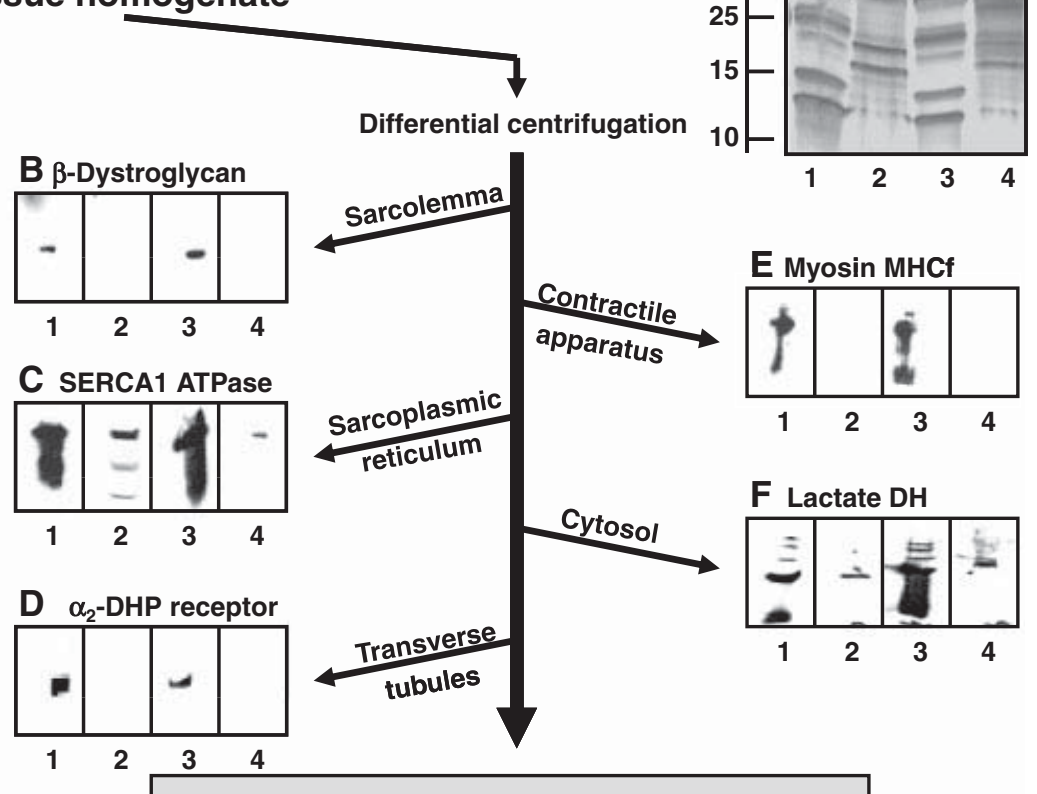

\section{Mitochondria-enriched fraction}

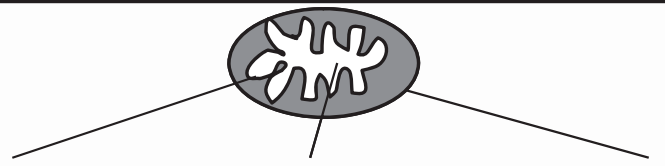

Marker of inner

Marker of

Marker of outer

mitochondrial membrane mitochondrial matrix mitochondrial membrane
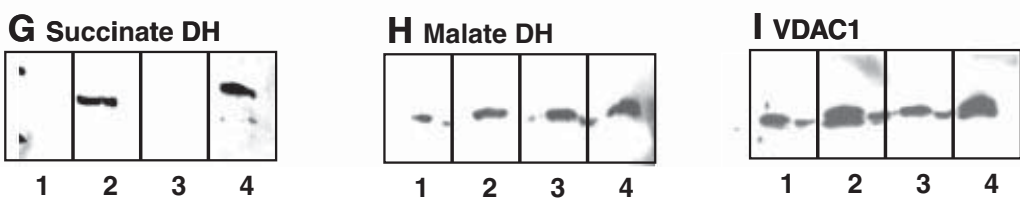

Figure 1. Evaluation of mitochondrial enrichment in subcellular preparations from rat muscle. Shown is a silverstained gel of crude and mitochondriaenriched muscle preparations from young adult and aged rat gastrocnemius muscle (A), as well as corresponding immunoblots labeled with antibodies to sarcolemmal $\beta$-dystroglycan (B), the fast SERCA1 isoform of the sarcoplasmic reticulum $\mathrm{Ca}^{2+}$-ATPase (C), the $\alpha_{2}$-subunit of the transversetubular dihydropyridine (DHP) receptor (D), fast MHCf myosin of the contractile apparatus (E), cytosolic lactate dehydrogenase (F), succinate dehydrogenase of the inner mitochondrial membrane (G), malate dehydrogenase of the mitochondrial matrix $(\mathrm{H})$, and the porin isoform VDAC1 of the outer mitochondrial membrane (I). Lanes 1-4 represent 3-month-old crude extract, 3month-old mitochondria-enriched fraction, 26-month-old crude extract and 26month-old mitochondria-enriched fraction, respectively. Molecular mass standards (in $\mathrm{kDa}$ ) are indicated on the left of panel (A). kinase [4]. An increased expression level was shown for 23 proteins that are clearly associated with mitochondria. Differential effects were observed for various non-mitochondrial elements. The Cy5-labelled master gels of Fig. 3 have marked and numbered all 39 changed protein spots from the mitochondria-enriched fraction. The mitochondrial protein species with the highest fold increase was identified as NADH dehydrogenase (spots 2, 4, 8, 9, 19, 20, $25)$. In addition, the mitochondrial inner membrane protein named mitofilin (spots 3, 28, 29, 30), peroxiredoxin PRX-III (spot 6), ATPase synthase (spot 10, 13), succinate dehydrogenase (spots 12, 23), mitochondrial fission protein Fis1 (spot 14), succinate-coenzyme A ligase (spot 18), acyl-coenzyme A dehydrogenase (spots 21, 26), porin isoform VDAC2 (spot 24), ubiquinol-cytochrome c reductase core I protein (spot 27) and prohibitin (spot 31) were found to be increased in aged gastrocnemius muscle. Other proteins with a changed expression, that are not directly located within mitochondria, were identified as glycolytic enzymes including enolase (spot 1), glyceraldehyde-3-phosphate dehydrogenase (spots 5, 32), phosphoglucomutase (spots 7 , 16), triosephosphate isomerase (spot 22) and aldolase (spot 38), as well as oxygen transporters such as myoglobin (spot 17) and hemoglobin (spots 35,36 ). While cytosolic malate 

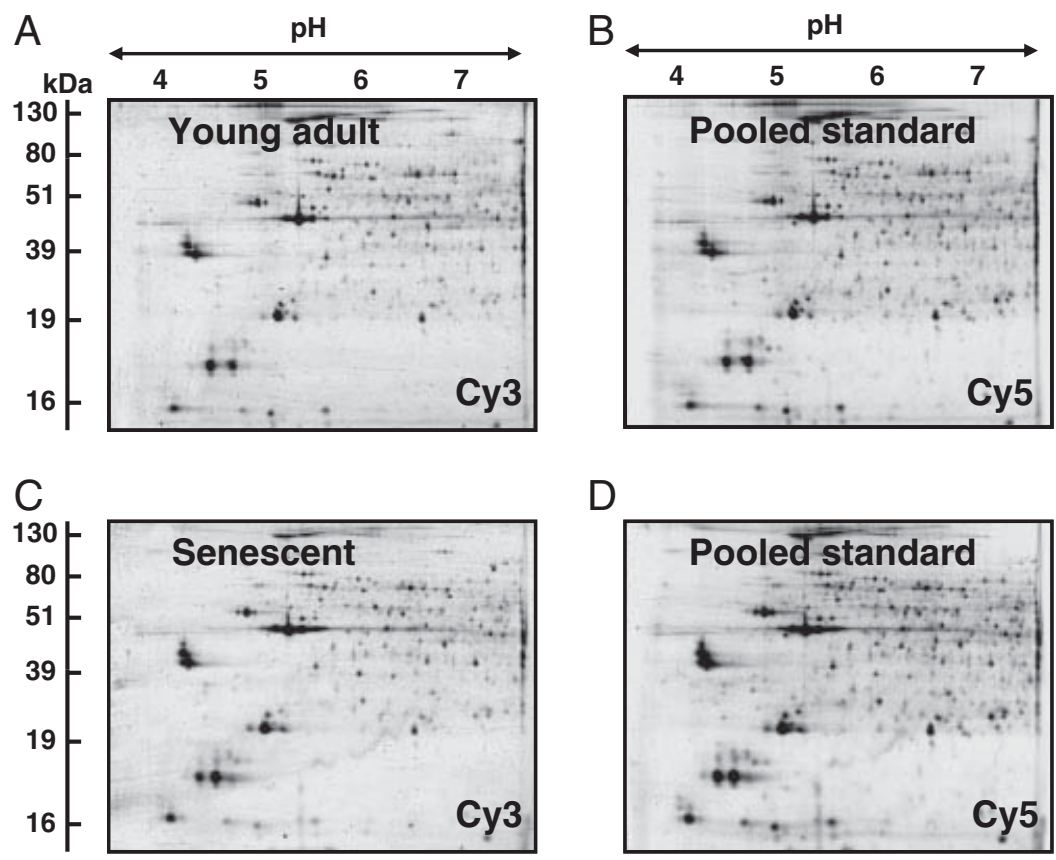

$\mathrm{D}$

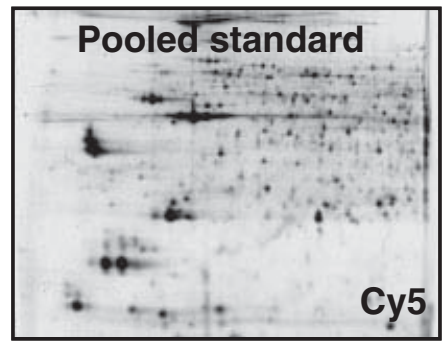

E
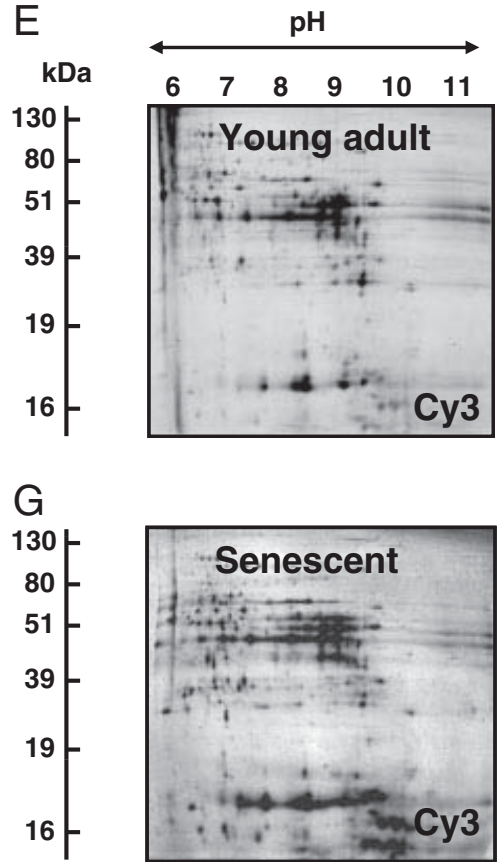

F

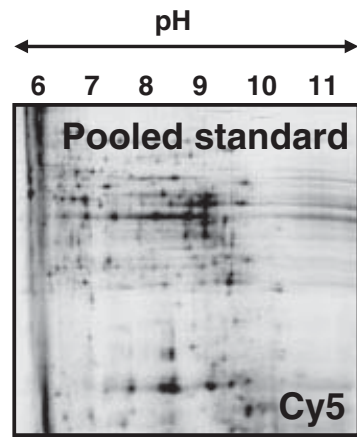

$\mathrm{H}$

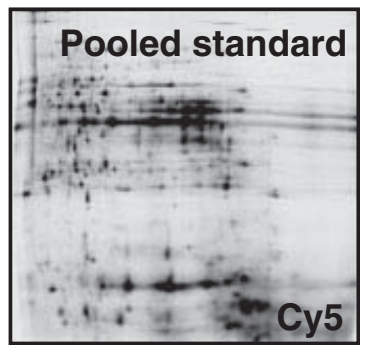

Figure 2. 2-D gel electrophoretic analysis of young adult versus senescent mitochondria. Shown are Cy3-labelled gels of the mitochondria-enriched fraction from young adult and senescent skeletal muscle, as well as Cy5-labelled gels containing pooled standards. Representative DIGE gels with electrophoretically separated mitochondrial proteins from 3-monthold $(A, E)$ versus senescent $(C, G)$ muscle fibers are shown for the $\mathrm{pH}$ 4-7 (A-D) and $\mathrm{pH}$ 6-11 $(\mathrm{E}-\mathrm{H})$ range. The lower and higher $\mathrm{pH}$-scale of the two different IEF approaches resulted in the separation of 726 and 722 2-D protein spots, respectively. The $\mathrm{pH}$-values of the first dimension gel system and molecular mass standards (in $\mathrm{kDa}$ ) of the second dimension are indicated on the top and on the left of the panels, respectively. dehydrogenase (spot 11) and the CAP1/DJ-1 protein (spot 15) showed increased levels in aged fibers, the expression of Ldb3 protein (spots 33, 37) and the intermediate filament component desmin (spot 34) were decreased. Interestingly, the only identified marker of the contractile apparatus, fast troponin I (spot 39), was decreased in aged fiber preparations, agreeing with a fast-to-slow transformation process during muscle aging. The low level of contractile proteins also shows that the subcellular fractionation protocol employed here has successfully removed the majority of the contractile apparatus in the mitochondria-enriched fraction.

\subsection{Increased mitochondrial proteins in aged skeletal muscle}

The enlarged images of DIGE-identified protein spots in Fig. 4 and accompanying graphical presentations of 


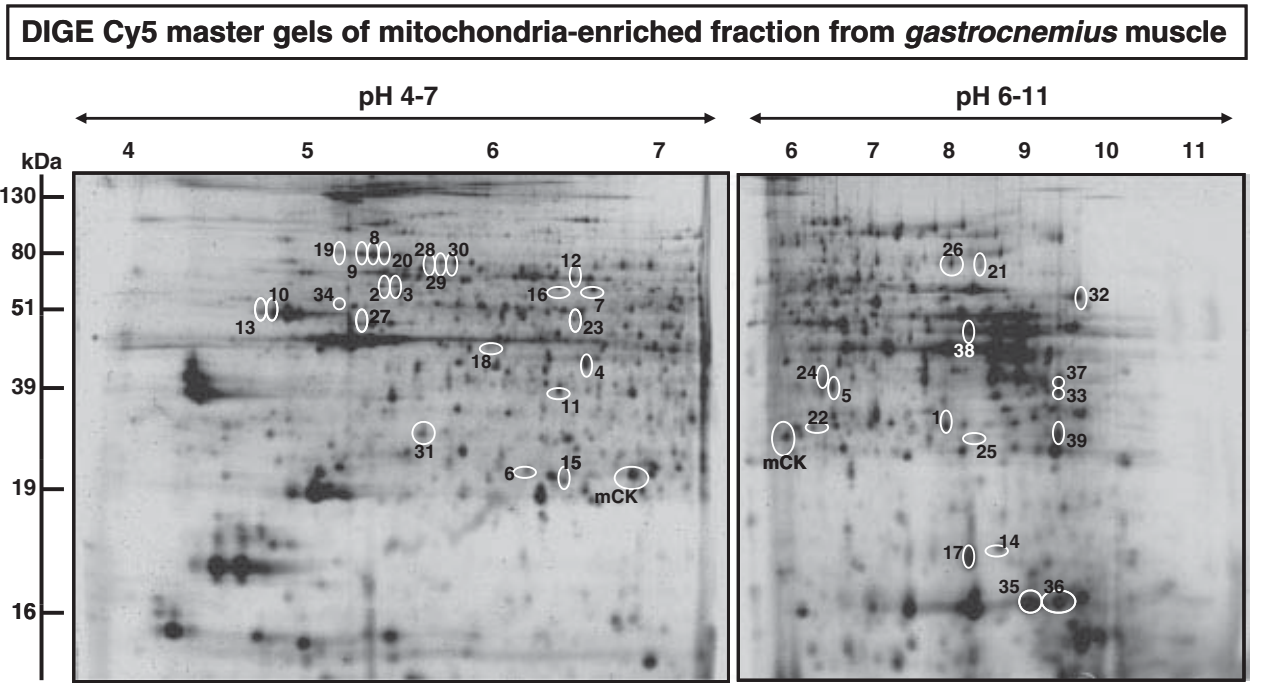

Figure 3. DIGE analysis of young adult versus senescent muscle mitochondria. Shown are Cy5-labelled master gels of the mitochondriaenriched fraction from rat skeletal muscle, covering both the $\mathrm{pH} \mathrm{4-7}$ and $\mathrm{pH}$ 6-11 range. Proteins with a drastically different expression level are marked by circles and are numbered 1 to 39. For optimum orientation, a landmark 2-D spot with unchanged abundance is indicated and marked $\mathrm{mCK}$, representing mitochondrial creatine kinase. See Supporting Information Table 1 for a detailed listing of muscle proteins with a changed abundance in senescent fibers. The pH-values of the first dimension gel system and molecular mass standards (in $\mathrm{kDa}$ ) of the second dimension are indicated on the top and on the left of the panels, respectively.

expression changes in individual protein species clearly demonstrates increased mitochondrial elements in aged muscle. This includes NADH dehydrogenase (Fig. 4A and $\mathrm{L})$, the inner mitochondrial membrane protein mitofilin (Fig. 4B, M), prohibitin (Fig. 4C and N), the porin isoform VDAC 2 (Fig. 4D and O), succinate dehydrogenase (Fig. 4E and $\mathrm{P}$ ), mitochondrial fission protein Fis1 (Fig. 4F and Q), acyl-coenzyme A dehydrogenase (Fig. 4G and R), peroxiredoxin isoform PRX-III (Fig. $4 \mathrm{H}$ and S), ubiquinol-cytochrome c reductase core I protein (Fig. 4I and T), succinatecoenzyme A ligase (Fig. 4J and U) and F1-ATPase (Fig. 4K and V). As illustrated in Fig. 5A, the majority of MS-identified proteins that exhibited a differential expression pattern are associated with mitochondria. Within the cohort of the mitochondrial complement, proteins derived mostly from the inner membrane system, as well as the outer membrane, matrix and intermembrane space (Fig. 5B).

\subsection{Immunoblot survey of mitochondrial biomarkers}

To validate the results of the DIGE analysis of the mitochondria-enriched fraction from young adult versus aged skeletal muscle, comparative immunoblotting of selected protein species was carried out. Following an initial survey with various antibodies and evaluation of their signal-tonoise-ratio, the binding patterns of four commercially available antibodies were found to be suitable for proper quantitative immunodecoration experiments. Many other antibodies to muscle antigens resulted in high background staining with unreliable densitometric data and therefore made their statistical analysis problematic (not shown). In contrast, the trend of an increased protein expression pattern of F1-ATPase (Fig. 6A), prohibitin (Fig. 6B), CAP1/ DJ1 protein (Fig. 6E) and succinate dehydrogenase (Fig. 6F) was confirmed by antibody labeling, as illustrated in representative immunoblots. The immunoblotting results agreed with the above-described findings from our DIGE analysis (Figs. 2-4; Supporting Information Table 1). The graphical presentations in Fig. 6C, D, G and $\mathrm{H}$ outlining the degree of immunolabeling of the four muscle proteins demonstrate an increased abundance in senescent fibers.

\subsection{Age-related increase in mitochondrial enzyme activity}

Standard enzymatic testing was employed to investigate potential changes in the activity of abundant mitochondrial markers in young adult versus senescent muscle. While the activity of the glycolytic enzyme aldolase was comparable between young and aged muscle preparations (Fig. 7A-C), a significant increase in activity was observed for mitochondrial proteins associated with respiratory chain complexes. The biochemical activity of the main constituent of mitochondrial complex-I, NADH dehydrogenase, was increased (Fig. 7D-F). This agrees with the proteomic finding of elevated expression levels of this mitochondrial enzyme. In analogy, the activity of the mitochondrial complex-II enzyme succinate dehydrogenase, which connects the respiratory chain to the citric acid cycle, was also increased in senescent muscle 


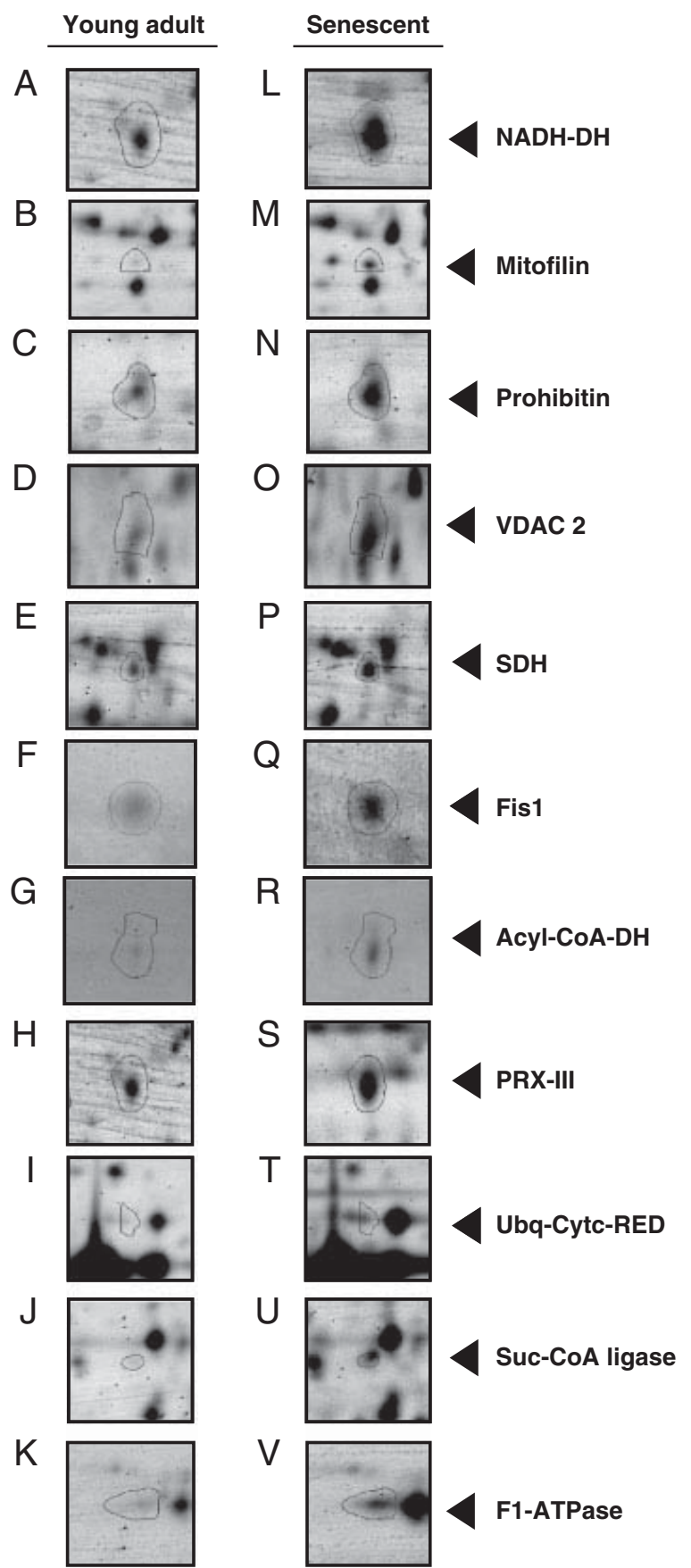

Figure 4. Increased expression of key mitochondrial proteins in aged skeletal muscle. Shown are expanded views of 2-D gels of the young adult muscle proteome (A-K) versus the senescent muscle proteome $(L-V)$. Shown are NADH dehydrogenase $(A, L)$, the inner mitochondrial membrane protein mitofilin $(B, M)$, prohibitin $(C, N)$, the porin isoform VDAC $2(D, O)$, succinate dehydrogenase $(E, P)$, mitochondrial fission protein Fis1 $(F, Q)$, acyl-coenzyme $A$ dehydrogenase $(G, R)$, peroxiredoxin isoform PRX-III $(\mathrm{H}, \mathrm{S})$, ubiquinol-cytochrome $\mathrm{c}$ reductase core I protein $(\mathrm{I}$, $\mathrm{T})$, succinate-coenzyme A ligase $(\mathrm{J}, \mathrm{U})$ and F1-ATPase $(\mathrm{K}, \mathrm{V})$. The position of 2-D spots representing distinct mitochondrial proteins is indicated by arrowheads on the right.

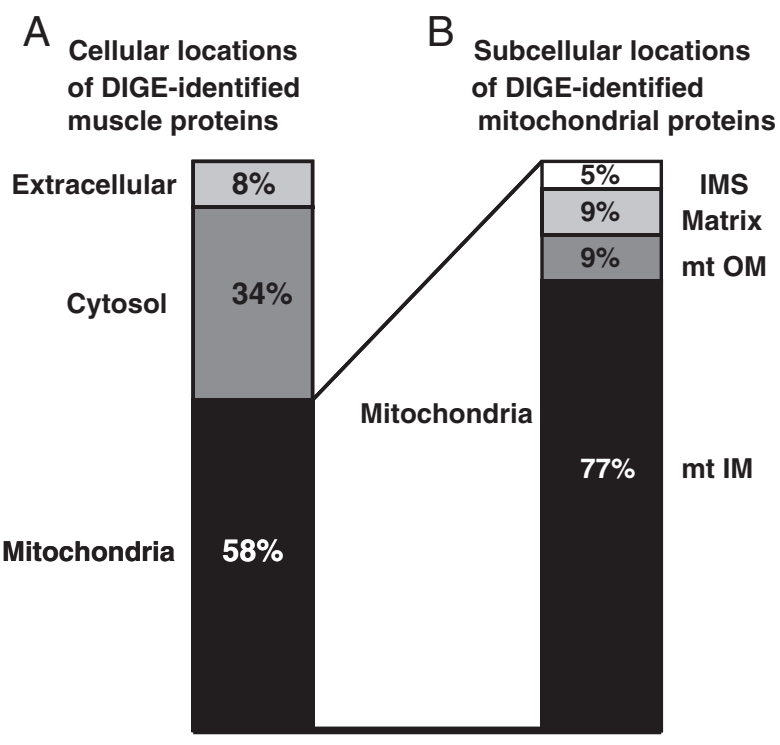

Figure 5. Subcellular distribution of DIGE-identified muscle proteins. Shown is the percent distribution of the cellular locations of DIGE-identified muscle proteins $(\mathrm{A})$ and the subcellular locations of DIGE-identified mitochondrial proteins (B). The majority of proteins exhibiting a changed expression level were found to be associated with mitochondria, i.e. the intermembrane space (IMS), the matrix, the mitochondrial outer membrane ( $\mathrm{mt} \mathrm{OM}$ ) and the mitochondrial inner membrane $(\mathrm{mt}$ IM) system.

(Fig. 7G-I). This biochemical result is also in agreement with the above-described proteomic profiling exercise and immunoblotting survey, and strongly supports the idea of an agedependent shift to more oxidative metabolism.

\subsection{Subcellular localization of mitochondrial biomarkers in aged fibers}

Confocal microscopy of transverse cryosections was used to investigate the subcellular localization of mitochondrial marker proteins in young adult versus senescent muscle. Figure 8 demonstrates an age-related increase in key mitochondrial proteins and confirms the results obtained by our DIGE-based proteomic profiling of aged gastrocnemius muscle. The fiber periphery and nuclei of young adult and aged muscle were visualized by immunolabeling of the sarcolemmal marker $\beta$-dystroglycan and DAPI staining, respectively (Fig. 8A-E). Comparative immunofluorescence labeling of phosphoglucomutase showed decreased levels of this glycolytic marker enzyme in aged fibers (Fig. 8A). In stark contrast, the mitochondria-associated proteins succinate dehydrogenase, DJ1, prohibitin and mitofilin exhibited increased levels in senescent muscle (Fig. 8B-E). While most mitochondrial labeling was found in the interior of fibers, mitochondrial clusters in the subsarcolemmal region have also been highlighted by confocal imaging. Succinate dehydrogenase appears to show a high degree of differential 
A

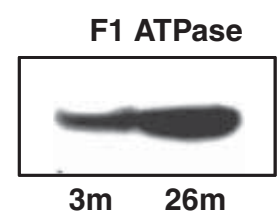

C

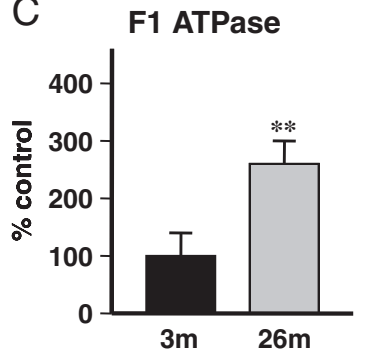

E
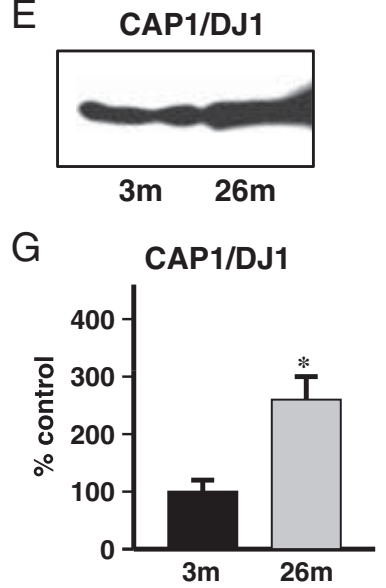

B

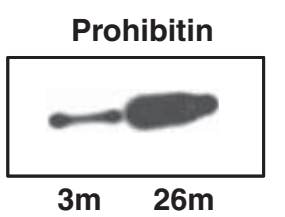

D

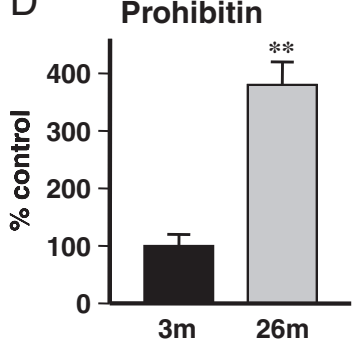

$\mathrm{F}$
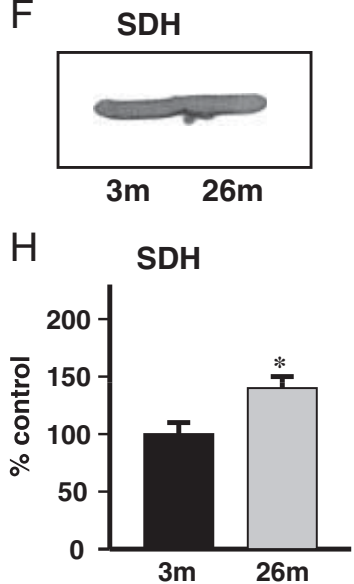

Figure 6. Immunoblotting survey of DIGE-identified muscle proteins with a differential expression pattern in senescent fibers. Shown is an expanded view of 1-D immunodecorated bands and the graphical presentation of the statistical evaluation of antibody labeling, representing mitochondrial F1-ATPase ( $A$, $C)$, prohibitin $(B, D), C A P 1 / D J 1$ protein $(E, G)$ and succinate dehydrogenase $(F, H)$. The comparative blotting was statistically evaluated using an unpaired Student's $t$-test $\left(n=5 ;{ }^{*} p<0.05\right.$; ${ }^{* *} p<0.01$ ). Lanes 1 and 2 represent the mitochondria-enriched fraction from 3-month-old and 26-month-old skeletal muscle fibers, respectively.

distribution in aged fiber types. Fluorescent scanning suggests an approximate two- to threefold increase of key mitochondrial markers in aged gastrocnemius muscle (Fig. 8B-E). The increased levels of mitochondrial proteins in senescent fibers agree with the above outlined gel electrophoretic and immunoblot analysis, and suggest an agedependent metabolic adaptation process with more aerobic processes in a slower-twitching fiber population.

\section{Discussion}

Since alterations in mitochondria are implicated in many developmental, physiological and pathological processes

[12], we have here studied the potential effect of aging on the mitochondrial proteome from skeletal muscle using the highly sensitive DIGE technique in combination with LCMS/MS analysis. Our main finding that the expression of a large array of key mitochondrial proteins belonging to the inner membrane system, matrix, outer membrane and intermembrane space is increased in senescent preparations agrees with the idea of an age-related shift to a slower contractile phenotype and more aerobic-oxidative metabolism [38]. The majority of changed mitochondrial protein species identified in this study were shown to be associated with the protein-rich inner membrane system. The inner mitochondrial membrane contains highly complex supramolecular protein assemblies involved in oxidative phosphorylation, ATP generation, metabolic flux and protein import [7]. Mitochondrial complex-I contains NADH dehydrogenase and is the largest respiratory chain unit. It is therefore not surprising that a large number of 2-D spots were identified as containing the highly abundant and complex enzyme NADH dehydrogenase. The principal constituent of complex-I exhibited drastically elevated levels and enzymatic activity in aged mitochondria, suggesting a shift to oxidative metabolism in senescent muscle. Another component of the mitochondrial respiratory chain with an increased abundance was identified as ubiquinol-cytochrome c reductase core I protein. In agreement with increased oxidative metabolism were the DIGE-identified elevated levels of acyl-coenzyme A dehydrogenase, an enzyme involved in the initial catalytic steps of mitochondrial fatty acid $\beta$-oxidation [7].

The mitochondrial complex-II enzyme succinate dehydrogenase transfers electrons from succinate to ubiquinone and forms a vital link between the citric acid cycle and the respiratory chain [71]. The abundance and activity of this essential entry point of electrons to the oxidative phosphorylation system appears to be increased in aged muscle, further supporting the hypothesis that senescent fibers exhibit a shift to oxidative metabolism. With respect to the citric acid cycle, the apparent up-regulation of the mitochondrial protein succinate-coenzyme A ligase is also important. This matrix enzyme catalyses the reversible conversion of succinyl-CoA and GDP to succinate and GTP. Importantly, the expression of the mitochondrial supramolecular complex-V that utilizes the proton gradient across the inner mitochondrial membrane for ATP generation was increased during aging. Subunits of the ATP synthase complex were shown both by DIGE analysis and immunoblotting to be clearly elevated in 26-month-old gastrocnemius fibers as compared to young adult muscle, which has also been shown in a recent comparative study of aged rat sciatic nerve and gastrocnemius muscle [35]. This finding supports the concept that senescent muscles adapt their bioenergetic needs to a more mitochondria-based ATP formation in a slower contracting fibers population. Such a metabolic shift would cause a greater demand for oxygen and therefore the observed increase in the oxygen-carrier 

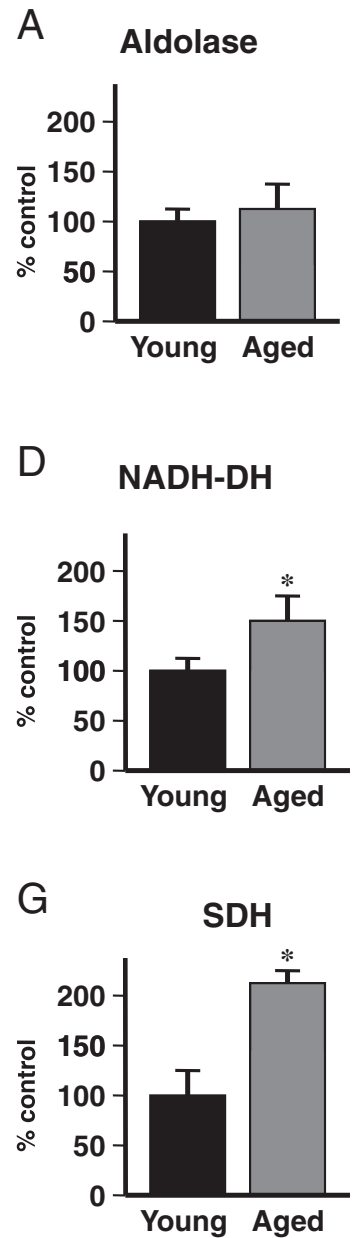

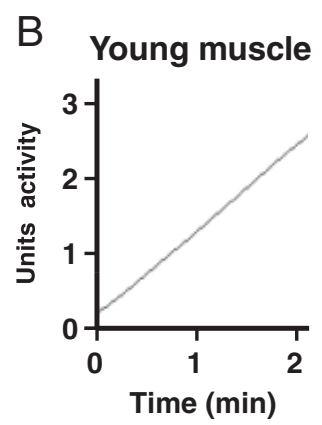

E Young muscle

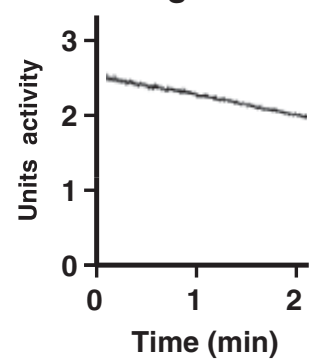

$\mathrm{H}$ Young muscle

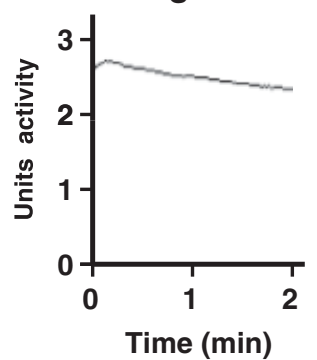

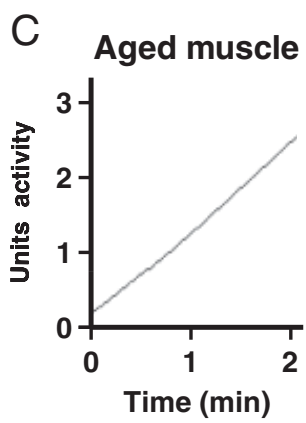

F Aged muscle

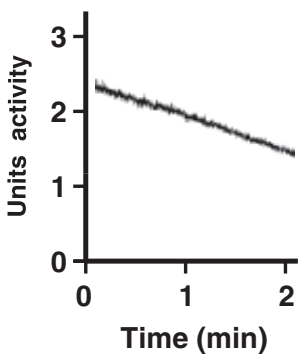

I Aged muscle

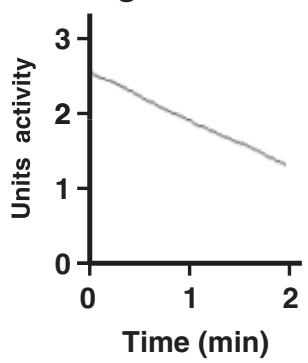

Figure 7. Changed biochemical activity of DIGE-identified mitochondrial proteins with a differential expression pattern in senescent fibers. Shown are representative results of enzyme assays measuring aldolase $(B, C)$, $\mathrm{NADH}$ dehydrogenase $(E, F)$ and succinate dehydrogenase $(\mathrm{H}, \mathrm{I})$ activity in young adult versus senescent gastrocnemius muscle preparations. Panels A, D and G illustrate graphically the statistical evaluation of the comparative enzyme testing using an unpaired Student's $t$-test $\left(n=5 ;{ }^{*} p<0.05\right)$. myoglobin in aged muscle agrees with the notion of increased oxidative metabolism [38].

The inner membrane protein mitofilin is considered indispensable for mitochondrial function [72], therefore the age-related increase in its skeletal muscle isoform could be interpreted as a compensatory mechanism to rescue damaged organelles and counter-act fiber degeneration. This would also agree with the higher concentration of the mitochondrial outer membrane fission protein Fis1 seen in aged fibers. The complex mitochondrial fission and fusion apparatus is responsible for the dynamics, division, subcellular distribution and organelle morphology, making Fis1 a key player in age-related adaptation and remodeling processes [73]. Isoforms of prohibitin are present in the inner mitochondrial membrane and play a role in the assembly of mitochondrial respiratory chain enzymes and exhibit chaperone activity. A proteomic survey of mitochondrial proteins in cardimyocytes from chronic stressed rats has shown a drastic increase in prohibitin [74]. This would suggest similar protective mechanisms in stressed mitochondria from aged skeletal muscle.
Since oxidative stress levels are considerably elevated in aged tissues, the increased density of peroxiredoxin isoform PRX-III and CAP1/DJ1 protein might act as an antioxidant defense shield. ROS are a dangerous by-product of the electron transport chain activity in mitochondria and PRXIII serves as a thioredoxin-dependent peroxidase that regulates intracellular $\mathrm{H}_{2} \mathrm{O}_{2}$ levels in an antioxidant defense pathway [75]. In addition, CAP1/DJ1 protein has also been reported to be involved in the cellular response to oxidative stress [76]. A key mitochondrial receptor present in the outer membrane system that was identified by our DIGE analysis of aged gastrocnemius fiber is a porin isoform that forms voltage-dependent anion channels. VDACs are a large family of pore-forming proteins that provide large membrane-spanning aqueous channels [77]. Increased levels of the VDAC2 transport protein agree with the concept of an age-related increase in mitochondrial function and a shift to more aerobic-oxidative metabolism in senescent fibers.

Other DIGE-identified proteins that are not directly present in mitochondria, but may be indirectly linked to this 
A
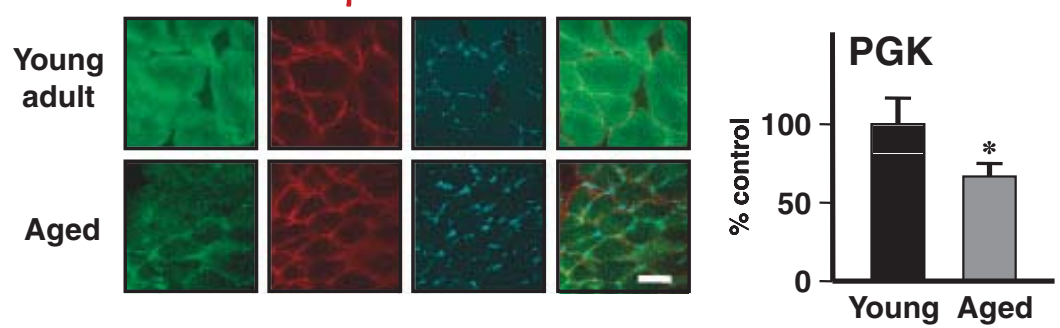

B

DJ1 / $\beta$-DG / DAPI
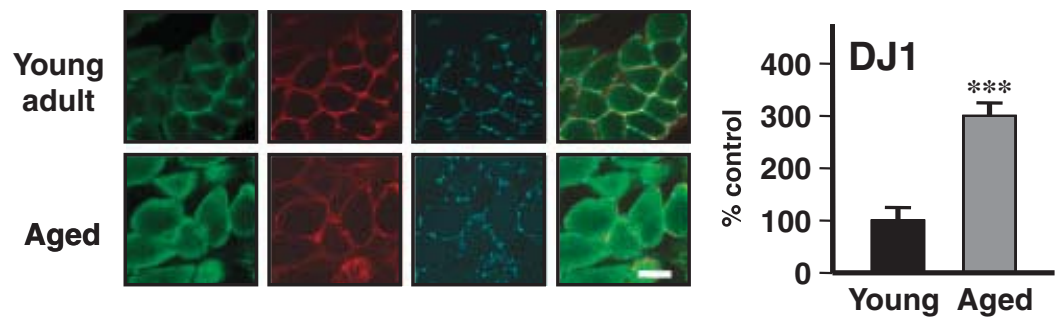

C

C Prohibitin / $\beta$-DG / DAPI
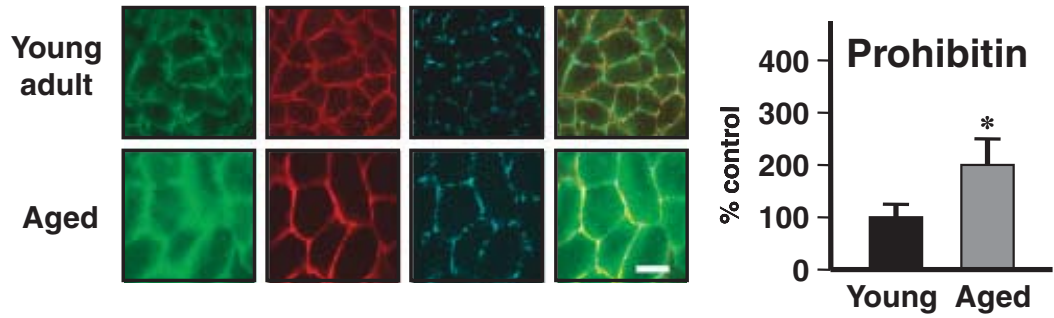

D SDH / $\beta$-DG / DAPI

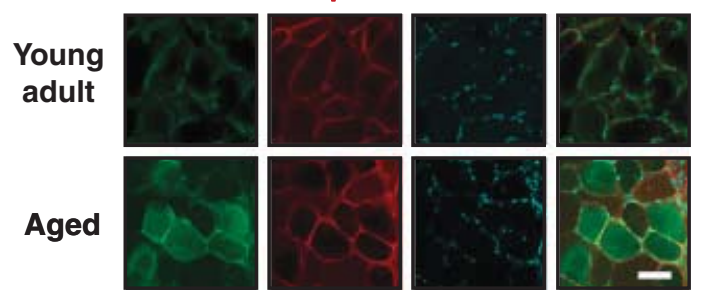

E

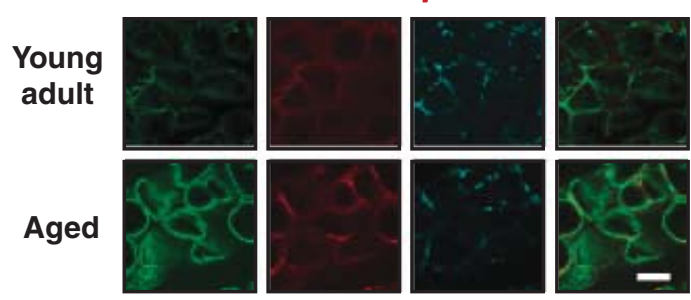

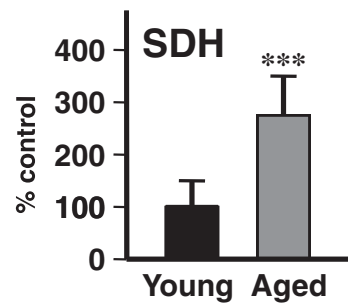

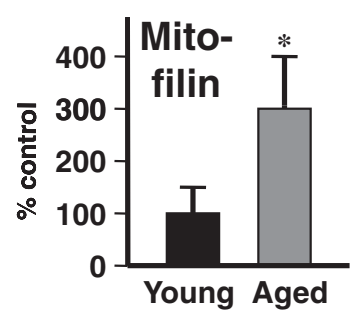

Figure 8. Confocal microscopy of DIGE-identified muscle proteins with a differential expression pattern in senescent fibers. Indirect immunofluorescence microscopy was employed for the localization of phosphoglucomutase (A), DJ1 protein (B), prohibitin (C), succinate dehydrogenase (D) and mitofilin (E). The fibers periphery was marked with antibody labeling to the surface membrane marker $\beta$-dystroglycan ( $\beta$ $D G ; A-E)$ and fibers nuclei were highlighted by DAPI staining. The pictures on the right side of the panels represent merged images. $B a r=40$ $\mu \mathrm{m}$. The relative intensity of fluorescent labeling was statistically evaluated using an unpaired Student's $t$-test $\left(n=5 ;{ }^{*} p<0.05 ;{ }^{* * *} p<0.001\right)$ and is graphically shown in panels $A$ to $E$. group of organelles, are glycolytic enzymes, metabolic carries, cytoskeletal elements and contractile proteins. Decreased expression levels were shown for Ldb3 protein and desmin. The Ldb3 protein is a PDZ domain-containing element that plays a role in cytoskeletal assembly and targeting and clustering of membrane proteins, and desmin is a component of the intermediate filament. Interestingly, mutations in the LDB3 gene are involved in the molecular pathogenesis of myofibrillar myopathy and dilated cardiomyopathy [78]. Thus, a reduction in both proteins may be 
involved in the functional decline of aged muscle fibers. A decrease of desmin was also shown by a recent proteomic study comparing the aged protein complement in crude extracts from rat sciatic nerve versus gastrocnemius muscle [35]. The differential expression and/or activity of certain glycolytic enzymes and reduced levels of hemoglobin subunits are difficult to interpret. Since these types of proteins are highly abundant and soluble, they can easily attach non-specifically to mitochondrial membranes during the subcellular fractionation protocol employed in this study. These findings might therefore not reflect their true expression status in aged muscle. On the other hand, glycolytic enzymes might form stable cytosolic complexes that interact with mitochondria in such a way that they cofractionate with mitochondria-enriched preparations. In agreement with a fast-to-slow transformation of aged muscle is the decreased abundance of the only DIGE-identified contractile protein, fast troponin-I. This troponin subunit might bind indirectly to mitochondria or is a soluble factor that becomes entrapped within the mitochondrial fraction. The lack of other contractile elements emphasizes the excellent separation protocol employed here.

In conclusion, the proteomic DIGE analysis of the mitochondria-enriched fraction from young adult versus senescent skeletal muscle presented in this report clearly showed increased levels of key metabolic and regulatory proteins during fibers aging. Alterations in the mitochondrial proteome included major elements of the supramolecular complexes that are involved in oxidative phosphorylation, ATP formation and fatty acid oxidation. Hence, skeletal muscle aging is clearly associated with a drastic shift to a slowertwitching senescent fibers population that exhibits a more aerobic-oxidative metabolism. In addition, increased levels of muscle proteins involved in antioxidant defense mechanisms, organelle fission and the renaturation process of malfolded proteins show that aged muscles appear to activate compensatory pathways to counter-act oxidative stress and protein degeneration. The mitochondrial markers described in this report represent novel and reliable candidates that should be considered for incorporation into the biomarker signature of skeletal muscle aging. Future studies focusing on these mitochondrial proteins may help in the design of superior diagnostic tools or the identification of new therapeutic targets for developing improved treatment options to eliminate agerelated muscle wasting.

Research was supported by a principal investigator grant from Science Foundation Ireland (SFI-04/IN3/B614) and equipment grants from the Irish Health Research Board (HRB-EQ/2003/3) and the Higher Education Authority (HEA-RERGS-07-NUIM). The authors thank Dr. Marina Lynch (Trinity College Dublin) for her generous help obtaining aged rat muscle and Ms. Caroline Batchlor (NUI Maynooth) for assistance with MS.

The authors have declared no conflict of interest.

\section{References}

[1] McBride, H. M., Neuspiel, M., Wasiak, S., Mitochondria: more than just a powerhouse. Curr. Biol. 2006, 16, R551-R560.

[2] Distler, A. M., Kerner, J., Hoppel, C. L., Proteomics of mitochondrial inner and outer membranes. Proteomics 2008, 8, 4066-4082.

[3] Brdiczka, D. G., Zorov, D. B., Sheu, S. S., Mitochondrial contact sites: their role in energy metabolism and apoptosis. Biochim. Biophys. Acta 2006, 1762, 148-163.

[4] Dolder, M., Wendt, S., Wallimann, T., Mitochondrial creatine kinase in contact sites: interaction with porin and adenine nucleotide translocase, role in permeability transition and sensitivity to oxidative damage. Biol. Signals Recept. 2001, 10, 93-111.

[5] Reichert, A. S., Neupert, W., Contact sites between the outer and inner membrane of mitochondria-role in protein transport. Biochim. Biophys. Acta 2002, 1592, 41-49.

[6] Scheffler, I. E., A century of mitochondrial research: achievements and perspectives. Mitochondrion 2001, 1, 3-31.

[7] Lee, C. P., Martens, M. E., in: Engel, A. G., FranziniArmstrong, C. (Eds.), Myology, McGraw-Hill Inc., New York 1994, pp. 624-647.

[8] Reifschneider, N. H., Goto, S., Nakamoto, H., Takahashi, R. et al., Defining the mitochondrial proteomes from five rat organs in a physiologically significant context using 2D blue-native/SDS-PAGE. J. Proteome Res. 2006, 5, 1117-1132.

[9] Johnson, D. T., Harris, R. A., French, S., Blair, P. V. et al., Tissue heterogeneity of the mammalian mitochondrial proteome. Am. J. Physiol. Cell Physiol. 2007, 292, C689-C697.

[10] Johnson, D. T., Harris, R. A., Blair, P. V., Balaban, R. S., Functional consequences of mitochondrial proteome heterogeneity. Am. J. Physiol. Cell Physiol. 2007, 292, C698-C707

[11] Forner, F., Foster, L. J., Campanaro, S., Valle, G., Mann, M., Quantitative proteomic comparison of rat mitochondria from muscle, heart, and liver. Mol. Cell Proteomics 2006, 5, 608-619.

[12] Chan, D. C., Mitochondria: dynamic organelles in disease, aging, and development. Cell 2006, 125, 1241-1252.

[13] Gustafsson, A. B., Gottlieb, R. A., Heart mitochondria: gates of life and death. Cardiovasc. Res. 2008, 77, 334-343.

[14] Siciliano, G., Volpi, L., Piazza, S., Ricci, G. et al., Functional diagnostics in mitochondrial diseases. Biosci. Rep. 2007, 27, 53-67.

[15] Lin, M. T., Beal, M. F., Mitochondrial dysfunction and oxidative stress in neurodegenerative diseases. Nature 2006, 443, 787-795.

[16] Trifunovic, A., Larsson, N. G., Mitochondrial dysfunction as a cause of ageing. J. Intern. Med. 2008, 263, 167-178.

[17] Lenaz, G., Bovina, C., D'Aurelio, M., Fato, R. et al., Role of mitochondria in oxidative stress and aging. Ann. NY Acad. Sci. 2002, 959, 199-213. 
[18] Chakravarti, B., Chakravarti, D. N., Oxidative modification of proteins: age-related changes. Gerontology 2007, 53, 128-139.

[19] Friguet, B., Bulteau, A. L., Petropoulos,I., Mitochondrial protein quality control: implications in ageing. Biotechnol. J. 2008, 3, 757-764.

[20] Figueiredo, P. A., Mota, M. P., Appell, H. J., Duarte, J. A., The role of mitochondria in aging of skeletal muscle. Biogerontology 2008, 9, 67-84.

[21] Chabi, B., Ljubicic, V., Menzies, K. J., Huang, J. H. et al., Mitochondrial function and apoptotic susceptibility in aging skeletal muscle. Aging Cell 2008, 7, 2-12.

[22] Figueiredo, P. A., Powers, S. K., Ferreira, R. M., Appell, H. J., Duarte, J. A., Aging impairs skeletal muscle mitochondrial bioenergetic function. J. Gerontol. A Biol. Sci. Med. Sci. 2009, 64, 21-33.

[23] Janssen, I., Heymsfield, S. B., Ross, R., Low relative skeletal muscle mass (sarcopenia) in older persons is associated with functional impairment and physical disability. J. Am. Geriatr. Soc. 2002, 50, 889-896.

[24] Hargreaves, M., Cameron-Smith, D., Exercise, diet, and skeletal muscle gene expression. Med. Sci. Sports Exerc. 2002, 34, 1505-1508.

[25] Hood, D. A., Irrcher, I., Ljubicic, V., Joseph, A. M., Coordination of metabolic plasticity in skeletal muscle. J. Exp. Biol. 2006, 209, 2265-2275.

[26] Doherty, T. J., Aging and sarcopenia. J. Appl. Physiol. 2003 95, 1717-1727.

[27] Thompson, L. V., Age-related muscle dysfunction. Exp. Gerontol. 2009, 44, 106-111.

[28] Edstrom, E., Altun, M., Bergman, E., Johnson, H. et al., Factors contributing to neuromuscular impairment and sarcopenia during aging. Physiol. Behav. 2007, 92, 129-135.

[29] Faulkner, J. A., Larkin, L. M., Claflin, D. R., Brooks, S. V., Agerelated changes in the structure and function of skeletal muscles. Clin. Exp. Pharmacol. Physiol. 2007, 34, 1091-1096.

[30] Campbell, W. W., Leidy, H. J., Dietary protein and resistance training effects on muscle and body composition in older persons. J. Am. Coll. Nutr. 2007, 26, 696S-703S.

[31] Piec, I., Listrat, A., Alliot, J., Chambon, C. et al., Differential proteome analysis of aging in rat skeletal muscle. FASEB J. 2005, 19, 1143-1145.

[32] Gelfi, C., Vigano, A., Ripamonti, M., Pontoglio, A. et al., The human muscle proteome in aging. J. Proteome Res. 2006, 5, 1344-1353.

[33] O'Connell, K., Gannon, J., Doran, P., Ohlendieck, K., Proteomic profiling reveals a severely perturbed protein expression pattern in aged skeletal muscle. Int. J. Mol. Med. 2007, 20, 145-153.

[34] Doran, P., O'Connell, K., Gannon, J., Kavanagh, M., Ohlendieck, K., Opposite pathobiochemical fate of pyruvate kinase and adenylate kinase in aged rat skeletal muscle as revealed by proteomic DIGE analysis. Proteomics 2008, 8, 364-377.

[35] Capitanio, D., Vasso, M., Fania, C., Moriggi, M. et al. Comparative proteomic profile of rat sciatic nerve and gastrocnemius muscle tissues in ageing by 2-D DIGE, Proteomics 2009, 9, 2004-2020.
[36] Lombardi, A., Silvestri, E., Cioffi, F., Senese, R. et al., Defining the transcriptomic and proteomic profiles of rat ageing skeletal muscle by the use of a cDNA array, 2D- and Blue native-PAGE approach. J. Proteomics 2009, 72, 708-721.

[37] Doran, P., Gannon, J., O'Connell, K., Ohlendieck, K., Aging skeletal muscle shows a drastic increase in the small heat shock proteins B-crystallin/HspB5 and cvHsp/HspB7. Eur. J. Cell Biol. 2007, 86, 629-640.

[38] Doran, P., Donoghue, P., O'Connell, K., Gannon, J., Ohlendieck, K., Proteomics of skeletal muscle aging. Proteomics 2009, 9, 989-1003.

[39] Gibson, B. W., The human mitochondrial proteome: oxidative stress, protein modifications and oxidative phosphorylation. Int. J. Biochem. Cell Biol. 2005, 37, 927-934.

[40] Da Cruz, S., Parone, P.A., Martinou, J. C., Building the mitochondrial proteome. Expert Rev. Proteomics 2005, 2, 541-551.

[41] Dimmer, K. S., Rapaport, D., Proteomic view of mitochondrial function. Genome Biol. 2008, 9, 209.

[42] Taylor, S. W., Fahy, E., Zhang, B., Glenn, G. M. et al., Characterization of the human heart mitochondrial proteome. Nat. Biotechnol. 2003, 21, 281-286.

[43] Gaucher, S. P., Taylor, S. W., Fahy, E., Zhang, B. et al., Expanded coverage of the human heart mitochondrial proteome using multidimensional liquid chromatography coupled with tandem mass spectrometry. J. Proteome Res. 2004, 3, 495-505.

[44] White, M. Y., Edwards, A. V. G., Cordwell, S. J., Van Eyk, J. E., Mitochondria: a mirror into cellular dysfunction in heart disease. Proteomics Clin. Appl. 2008, 2, 845-861.

[45] McDonald, T., Sheng, S., Stanley, B., Chen, D. et al., Expanding the subproteome of the inner mitochondria using protein separation technologies: one- and two-dimensional liquid chromatography and two-dimensional gel electrophoresis. Mol. Cell Proteomics 2006, 5, 2392-2411.

[46] Da Cruz, S., Martinou, J. C., Purification and proteomic analysis of the mouse liver mitochondrial inner membrane. Methods Mol. Biol. 2008, 432, 101-116.

[47] Pesce, V., Cormio, A., Fracasso, F., Vecchiet, J. et al., Agerelated mitochondrial genotypic and phenotypic alterations in human skeletal muscle. Free Radic. Biol. Med. 2001, 30, 1223-1233.

[48] Chang, J., Van Remmen, H., Cornell, J., Richardson, A., Ward, W. F., Comparative proteomics: characterization of a two-dimensional gel electrophoresis system to study the effect of aging on mitochondrial proteins. Mech. Ageing Dev. 2003, 124, 33-41.

[49] Dencher, N. A., Goto, S., Reifschneider, N. H., Sugawa, M., Krause, F., Unraveling age-dependent variation of the mitochondrial proteome. Ann. NY Acad. Sci. 2006, 1067, 116-119.

[50] Dencher, N. A., Frenzel, M., Reifschneider, N. H., Sugawa, M., Krause, F., Proteome alterations in rat mitochondria caused by aging. Ann. NY Acad. Sci. 2007, 1100, 291-298.

[51] Chang, J., Cornell, J. E., Van Remmen, H., Hakala, K. et al., Effect of aging and caloric restriction on the mitochondrial proteome. J. Gerontol. A Biol. Sci. Med. Sci. 2007, 62, 223-234. 
[52] Viswanathan, S., Unlu, M., Minden, J. S., Two-dimensional difference gel electrophoresis. Nat. Protoc. 2006, 1, 1351-1358.

[53] Tonge, R., Shaw, J., Middleton, B., Rowlinson, R., Rayner, S. et al., Validation and development of fluorescence twodimensional differential gel electrophoresis proteomics technology. Proteomics 2001, 1, 377-396.

[54] Marouga, R., David, S., Hawkins, E., The development of the DIGE system: 2D fluorescence difference gel analysis technology. Anal. Bioanal. Chem. 2005, 382, 669-678.

[55] Doran, P., Gannon, J., O'Connell, K., Ohlendieck, K., Proteomic profiling of animal models mimicking skeletal muscle disorders. Proteomics Clin. Appl. 2007, 1, 1169-1184.

[56] O'Connell, K., Doran, P., Gannon, J., Ohlendieck, K., Lectinbased proteomic profiling of aged skeletal muscle: decreased pyruvate kinase isozyme M1 exhibits drastically increased levels of N-glycosylation. Eur. J. Cell Biol. 2008, 87, 793-805.

[57] Bradford, M. M., A rapid and sensitive method for the quantitation of microgram quantities of protein utilizing the principle of protein-dye binding. Anal. Biochem. 1976, 72, 248-254.

[58] Kane, L. A., Yung, C. K., Agnetti, G., Neverova, I., Van Eyk, J. E., Optimization of paper bridge loading for 2-DE analysis in the basic $\mathrm{pH}$ region: application to the mitochondrial subproteome. Proteomics. 2006, 6, 5683-5687.

[59] Srere, P. A., Citrate synthase. Methods Enzymol. 1969, 13, 3-11.

[60] Heukeshoven, J., Dernick, R., Simplified method for silver staining of proteins in polyacrylamide gels and the mechanism of silver staining. Electrophoresis, 1985, 6, 103-112.

[61] Bradd, S. J., Dunn, M. J., Analysis of membrane proteins by western blotting and enhanced chemiluminescence. Methods Mol. Biol. 1993, 19, 211-218.

[62] Doran, P., Martin, G., Dowling, P., Jockusch, H., Ohlendieck, K., Proteome analysis of the dystrophin-deficient MDX diaphragm reveals a drastic increase in the heat shock protein cvHSP. Proteomics 2006, 6, 4610-4621.

[63] Donoghue, P., Doran, P., Wynne, K., Pedersen, K. et al., Proteomic profiling of chronic low-frequency stimulated fast muscle. Proteomics 2007, 7, 3417-3430.

[64] Doran, P., Wilton, S. D., Fletcher, S., Ohlendieck, K., Proteomic profiling of antisense-induced exon skipping reveals reversal of pathobiochemical abnormalities in dystrophic mdx diaphragm. Proteomics 2009, 9, 671-685.

[65] Karp, N. A., Lilley, K. S., Maximising sensitivity for detecting changes in protein expression: experimental design using minimal CyDyes. Proteomics 2005, 5, 3105-3115.

[66] Karp, N. A., Feret, R., Rubtsov, D. V., Lilley, K. S., Comparison of DIGE and post-stained gel electrophoresis with both traditional and SameSpots analysis for quantitative proteomics. Proteomics 2008, 8, 946-948.

[67] Karp, N. A., Lilley, K. S., Investigating sample pooling strategies for DIGE experiments to address biological variability. Proteomics 2009, 9, 388-397.

[68] Fang, J., Beattie, D. S., Novel FMN-containing rotenoneinsensitive NADH dehydrogenase from Trypanosoma brucei mitochondria: isolation and characterization. Biochemistry 2002, 41, 3065-3072.

[69] Drechsler, E. R., Boyer, P. D., Kowalsky, A. G., The catalytic activity of carboxypeptidase-degraded aldolase. J. Biol. Chem. 1959, 234, 2627-2634.

[70] Krahenbuhl, S., Chang, M., Brass, E. P., Hoppel, C. L., Decreased activities of ubiquinol:ferricytochrome c oxidoreductase (complex III) and ferrocytochrome c:oxygen oxidoreductase (complex IV) in liver mitochondria from rats with hydroxycobalamin[c-lactam]-induced methylmalonic aciduria. J. Biol. Chem. 1991, 266, 20998-21003.

[71] Dudkina, N. V., Sunderhaus, S., Boekema, E. J., Braun, H. P., The higher level of organization of the oxidative phosphorylation system: mitochondrial supercomplexes. J. Bioenerg. Biomembr. 2008, 40, 419-424.

[72] John, G. B., Shang, Y., Li, L., Renken, C. et al., The mitochondrial inner membrane protein mitofilin controls cristae morphology. Mol. Biol. Cell. 2005, 16, 1543-1554.

[73] Serasinghe, M. N., Yoon, Y., The mitochondrial outer membrane protein hFis1 regulates mitochondrial morphology and fission through self-interaction. Exp. Cell Res. 2008, 314, 3494-3507.

[74] Liu, X. H., Qian, L. J., Gong, J. B., Shen, J. et al., Proteomic analysis of mitochondrial proteins in cardiomyocytes from chronic stressed rat. Proteomics 2004, 4, 3167-3176.

[75] Cao, Z., Bhella, D., Lindsay, J. G., Reconstitution of the mitochondrial PrxIII antioxidant defence pathway: general properties and factors affecting Prxlll activity and oligomeric state. J. Mol. Biol. 2007, 372, 1022-1033.

[76] Bonifati, V., Oostra, B. A., Heutink, P., Linking DJ-1 to neurodegeneration offers novel insights for understanding the pathogenesis of Parkinson's disease. J. Mol. Med. 2004, $82,163-174$.

[77] De Pinto, V., Reina, S., Guarino, F., Messina, A., Structure of the voltage dependent anion channel: state of the art. J. Bioenerg. Biomembr. 2008, 40, 139-147.

[78] Marziliano, N., Mannarino, S., Nespoli, L., Diegoli, M. et al., Barth syndrome associated with compound hemizygosity and heterozygosity of the TAZ and LDB3 genes. Am. J. Med. Genet. 2007, 143A, 907-915. 